\title{
ANALYSIS OF FACTORS DETERMINING THE EFFICIENCY OF IMPORT TRANSACTIONS IMPLEMENTED BY A COMPANY UNDER ECONOMIC UNCERTAINTY
}

\section{O. Martyanova ${ }^{1}$}

DOI: http://doi.org/10.15350/L_3/3/1

Abstract

The paper presents methodology for evaluation of import transaction efficiency based on the model of indicative figures, which determine economic relevance of carrying out this type of international trade activity with due consideration of the factors focused on accomplishing both operative and strategic import-related goals pursued by an economic entity.

Keywords: analysis, percentage variance graph, import transactions, Markovian processes, ex-ante standard, controlled variance, internal environment factor, efficiency.

One of the consequences of poor barley yield in 2017 is expected to be a pricing pressure on the beer producers [3]. Should beer brewers make changes in the brewery receipts, it will slightly hold down the prices of barley. There will be an increase of winter crop share on the market, as well as an increasing demand for barley varieties previously non-demanded. However, brewers currently have to adapt to the challenging year as high prices for barley will exert a negative impact on the efficiency of those brewery businesses which do not have longterm barley purchase agreements, and fit within the amount allocated for this purpose, which will result in differences between actual and expected results.

Variance analysis is very important for the companies involved in international trade, as these variances influence the company's efficiency. The evaluation of variance in the context of research into efficiency of international transactions is carried out based on exclusion principle, which enables the company to focus on those processes of international trade, where certain actions are required, rather than waste time on something, which doesn't bring the expected outcomes. We believe that the issues requiring thorough exploration in terms of efficiency analysis of international transactions, need a special approach. First of all, the study of these transactions is connected with expenses; secondly, it determines the adequacy of the decision made. Therefore, the decision made on the variance analysis when evaluating the efficiency of international transactions may be schematically represented as follows in Figure 1.

\footnotetext{
1Olga Martyanova, Candidate of Economic Sciences, doctoral candidate the Orel State University of Economics and Trade, Russia.
} 


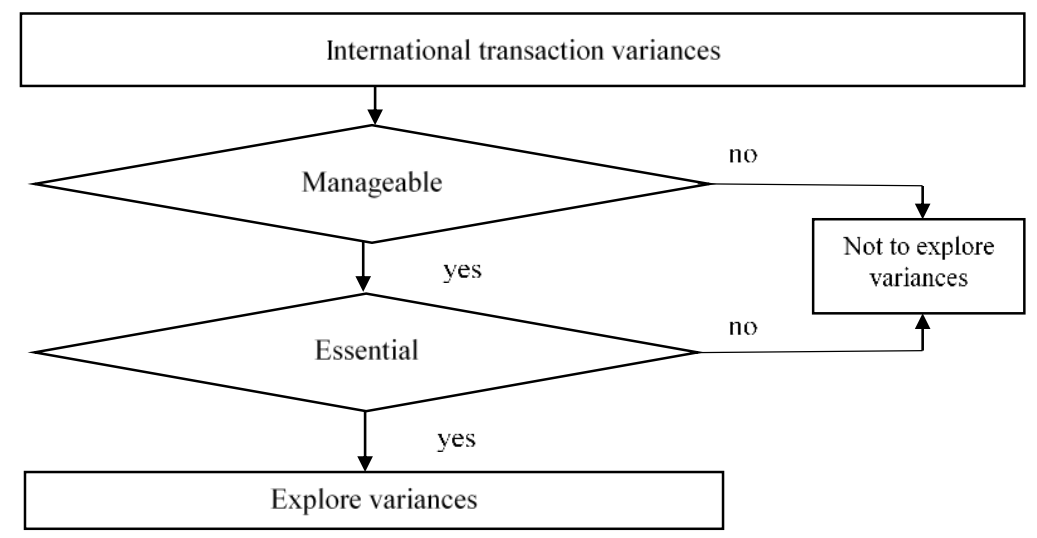

Figure 1. Decision making scheme of evaluating variances when carrying out international transactions Source: compiled by the author

In case the variance is manageable, i.e. emerges as a result of factors controlled by the importer, then these variances should be explored because a company can eliminate these variances or use them in order to enhance the efficiency of its international transactions. Unmanageable variances emerge as a result of factors beyond the company's control, and are not worth examining, because a company may not influence these variances.

In our view, in this case importers face unmanageable variance, i.e. a variance, which emerges as a result of factors beyond the company's control. Therefore, the adverse impact of raw material pricing occurred as a result of an increase in global barley prices cannot be regarded as a variance within the importer's control, and it is not a subject of the importer's responsibility. A manageable variance is, on the contrary, emerging as a result of factors within the control of an economic entity. Thereby, it is necessary to examine such variances under economic uncertainty, as those can be either mitigated or, on the contrary, used for the benefit of the importer.

Thus, the companies should act with due diligence when dealing with variance examination, because it causes extra expenses and concerns the value of the obtained information, which aims to reduce uncertainty in international trade. Before involving a consultancy agency into evaluation of international trade transactions, it is necessary to estimate the amount due for the information provided. A detailed procedure for the estimate of information costs necessary to choose one out of three international suppliers providing international raw materials depending on the market reaction to the changes in international trading activity based on the data provided by the company manufacturing upmarket beer brand is presented in Table 1 .

The analysis of results presented in Table 1 proves that is a company is lacking accurate information, then the optimum solution for this situation will be 
choosing a foreign contract suggested by the Asian supplier, because this supplier is associated with the largest amount of net cash inflow, equalling 739.86 thousand euro.

Table 1

Evaluation of information cost when selecting an import contract

\begin{tabular}{|c|c|c|c|c|}
\hline \multirow[t]{2}{*}{$\begin{array}{l}\text { Market reaction to } \\
\text { the changes of in- } \\
\text { ternational trade } \\
\text { conditions/ Indica- } \\
\text { tor }\end{array}$} & \multirow[t]{2}{*}{$\begin{array}{l}\text { Likelihood of } \\
\text { changes in the } \\
\text { conditions of } \\
\text { international } \\
\text { trade }\end{array}$} & EU supplier & $\begin{array}{l}\text { North Ameri- } \\
\text { can supplier }\end{array}$ & $\begin{array}{l}\text { Asian sup- } \\
\text { plier }\end{array}$ \\
\hline & & \multicolumn{3}{|c|}{ Net cash inflow, thousand euro } \\
\hline Strong & 0.5 & 949.00 & 1131.50 & 1241.00 \\
\hline Moderate & 0.3 & 492.75 & 234.33 & 352.59 \\
\hline Weak & 0.2 & 92.71 & 205.86 & 67.89 \\
\hline \multicolumn{5}{|c|}{ In the absence of accurate information: } \\
\hline $\begin{array}{l}\text { The expected value } \\
\text { of net cash inflow } \\
\text { per year, thousand } \\
\text { euro }\end{array}$ & 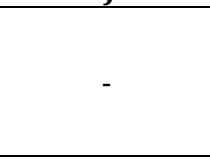 & 640.87 & 677.22 & 739.86 \\
\hline \multicolumn{5}{|c|}{ In the presence of accurate information: } \\
\hline $\begin{array}{l}\text { The expected value } \\
\text { of net cash inflow } \\
\text { per year, thousand } \\
\text { euro: }\end{array}$ & 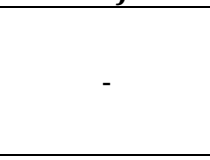 & - & - & - \\
\hline $\begin{array}{l}\text { - strong market } \\
\text { reaction, thousand } \\
\text { euro }\end{array}$ & 0.5 & 474.50 & 565.75 & 620.50 \\
\hline $\begin{array}{l}\text { - moderate mar- } \\
\text { ket reaction, thou- } \\
\text { sand euro }\end{array}$ & 0.3 & 147.83 & 70.30 & 105.78 \\
\hline $\begin{array}{l}\text { - weak market re- } \\
\text { action, thousand } \\
\text { euro }\end{array}$ & 0.2 & 18.54 & 41.17 & 13.58 \\
\hline
\end{tabular}

Source: calculated by the author

Should an importer have accurate information, the situation would be different. Thus, if the examination predicts a strong market reaction to the change of international trade conditions, then it would be reasonable to select an Asian importer. In this case the net cash inflow will amount to 620.50 thousand euro per year. Provided the market reaction to changes is moderate, it is advisable to select a contract offered by the EU supplier, which will ensure an annual cash inflow in the amount of 147.83 thousand euro. If examination predicts a weak market reaction, then it is recommended to make a contract with a North American supplier, as this option will ensure net cash inflow in the amount of 41.17 thousand euro. Thus, once the expected value of net cash inflow equals to 809.5 thou- 
sand euro, provided there is accurate information, the cost of this accurate information will equal to 96.64 thousand euro. This is the maximum amount due to payment by the company to the consultancy agency for this information.

In order to give an adequate evaluation of the efficiency of international transactions in line with the operating conditions of the company, the company should separately consider operational and expected variances, as it will enable the company to obtain the benchmarks in comparison with the original criteria. This is because operational variances, unlike the expected ones, are based on revised standards and reflect the result level reached by an importer when carrying out international transactions. Planned variances emerge when, in the light of the circumstances becoming known, the original standards turn to be inadequate.

Distinguishing between planned and operating variances enable a company to identify their origin. Thus, if a production department is unable to influence the planned variances, therefore, cannot be responsible for them, this means that the time spent by the department on examining these variances will not bring any benefit. Planned variances may emerge as a result of setting incorrect benchmarks by the budget department, hence the department forming the budget based on ex-ante standards should be responsible for those.

In order to have a clear idea on the efficiency of international transactions over the period under study it is necessary to determine the cause of variances, which may imply either using inadequate standards or their inefficient application. So as to define the causes of variances, the importer should develop a new revised plan with ex-post standards, based on the estimates, which were revised after the budget was adopted and the primary standards were determined. In our view, it is important for the standards to take into consideration the market tendencies in the sphere of import known at the time of their determination, as this will enable the company management to avoid the emergence of adverse standards and suggests the effectiveness of standard development system.

The calculation of the planned variances may be carried out using the methods of varying difficulty. In our view, in order to solve this problem, an importer should refer to the method which implies carrying out only three following steps:

Step 1: calculate a gap between ex-ante and ex-post standards.

Step 2: form a planning variance, emerging as a result of calculations carried out when implementing step 1.

Step 3: calculate operating variances based on ex-post standards.

We believe that the simplicity of the method is its major advantage, as the results obtained raise a company's motivation of referring to it when analyzing effective import transactions.

Given that a variance analysis is aimed at improving the efficiency of import transaction management, it is necessary to establish criteria making it possible to make a decision on the relevance of their examination. In our view, these criteria should be developed based on the factors, which can be taken into consideration when making such a decision: the amount of variance, likelihood that a variance is manageable; correlation between variances; and a type of the stand- 
ards applied. Pro arguments for the use of these factors when creating a benchmarking system for evaluating the efficiency of import transactions prove, there is no point in examining minor variances or variances, which exert minimum impact on the overall result. Therefore, an importer can be recommended to set a criterion according to which any variance exceeding the standard costs by $5 \%$ should be thoroughly analysed. A different approach can be used when forming a criterion: first it is necessary to determine the reference values and if a variance value exceeds the set limit, it should be examined.

At the same time, we believe it is irrelevant to analyse variances which are regarded as circumstances that a company cannot change, unmanageable variances will remain the same, even if there is a detailed analysis on the reasons behind these variances. Thus, it is more difficult for a beer importer to control the variance on raw material cost in comparison with the variance on the use of this raw material. It is so because cost variance is mainly determined by the external factors, which make it unmanageable. However, the cost variance on raw material may also be caused by inefficient policy of a company regarding procurement. In any case, until variances are analysed, the source of their occurrence will remain unknown.

In our opinion, the importer should focus on the variances, which are really important and can be changed. In order to do so, it is necessary to estimate possible analysis costs and compare them with the expenses incurred by a company if these variances will continue into the future.

Correlation of variances is also an issue in import transactions as adverse variances of one process may be correlated with the favourable variances of another process. When an importer purchases cheap raw material from an international supplier, on the one hand it ensures favourable variances in terms of pricing, on the other hand, the quality of cheap raw material might be lower, therefore more difficult to process, which might result in adverse variances in terms of raw material use and performance.

When evaluating the efficiency of import transactions it is important to bear in mind the type of the standards used. Even provided the standards are ideally developed, there are variance risks of inevitable losses. For this reason, it is important for the company to define the level of expected variances when carrying out import transactions, i.e. such value of adverse variances, which would be adequate for a company. But carrying out these calculations needs taking into consideration inflation, upward pricing tendency, which can counter-balance positive price variances occurring at the beginning of the year to their unfavourable variances at the end, when the effective prices will be on the increase if the standard price is established as a mean annual price. Thus, the set criteria based on the above stated factors allow to make an adequate decision with regard to variance analysis in international trade.

One of the factors taken into consideration when making a decision whether the variance analysis is necessary or not is its amount. However, in some cases an importer finds it difficult to evaluate the scale or tendency of variances provided they are represented in absolute values. In such cases a company may be recommended to use percentage variance graphs in the format, which facilitates 
data interpretation and allows to determine future trends in the sphere of import. In order to reveal tendencies in up-market beer production based on imported raw material, let us provide an evaluation of variances followed by the representation of their temporal dynamics, necessary to make a decision on changing raw material purchasing policy due to fluctuations of beer output caused by shifting patters in customer demand. For the purpose of our research we used the data available from the annual reports and data publications of an industrial company. The results of percentage variation calculations inclusive of expenditures on purchasing an upmarket ingredient as well as the data on production volume and fixed variations of raw material expenditures over the 4 month period of 2017 are provided in Table 2.

Table 2

Evaluation of percentage variances in terms of price and volume of the material used over the period from September 2017 to December 2017

\begin{tabular}{|c|c|c|c|c|}
\hline \multirow[t]{2}{*}{ Parameter } & \multicolumn{4}{|c|}{ Four-month period of 2017} \\
\hline & September & October & November & December \\
\hline $\begin{array}{l}\text { Purchase } \\
\text { amount, kg }\end{array}$ & 4234.0 & 1803.1 & 3358.0 & 2263.0 \\
\hline $\begin{array}{l}\text { Price per unit, } \\
\text { euro }\end{array}$ & 25.33 & 25.33 & 25.33 & 25.33 \\
\hline $\begin{array}{l}\text { Raw material } \\
\text { price variance, } \\
\text { euro }\end{array}$ & $4445.70 \quad(n)$ & $1514.75 \quad$ (n) & $2350.60 \quad(n)$ & $1109.60 \quad(n)$ \\
\hline $\begin{array}{l}\text { Variance in the } \\
\text { volume of used } \\
\text { raw material, } \\
\text { euro }\end{array}$ & $5927.60 \quad(n)$ & $2146.20 \quad(n)$ & $3055.05 \quad(n)$ & $1584.10 \quad(\mathrm{n})$ \\
\hline $\begin{array}{l}\text { Standard cost of } \\
\text { materials, euro }\end{array}$ & 107251.45 & 45674.33 & 85061.50 & 57324.05 \\
\hline $\begin{array}{l}\text { Price variance } \\
\text { calculated as a } \\
\text { percentage of ag- } \\
\text { gregate standard } \\
\text { cost of material, } \\
\%\end{array}$ & $4 \quad(n)$ & $3 \quad$ (n) & $3 \quad(n)$ & (n) \\
\hline $\begin{array}{l}\text { Volume variance } \\
\text { of material used } \\
\text { calculated as a } \\
\text { percentage of ag- } \\
\text { gregate standard } \\
\text { cost of material, } \\
\%\end{array}$ & $6 \quad(n)$ & $5 \quad$ (n) & $4 \quad(n)$ & (n) \\
\hline
\end{tabular}

Source: Compiled by the author

Graphic interpretation of the obtained results is provided in Figure 2. It shows that the graph in each variance demonstrates a clear trend. It should be noted that this trend is not clearly visible when considering data provided in ab- 
solute values. The analysis of the graph proves that in September 2017 the ingredient purchased abroad was $4 \%$ more expensive than the standard cost of raw material. This might be the reason of its unfavourable variance in terms of its use, which comprised $6 \%$ of the aggregate standard raw material cost necessary for the actual production.

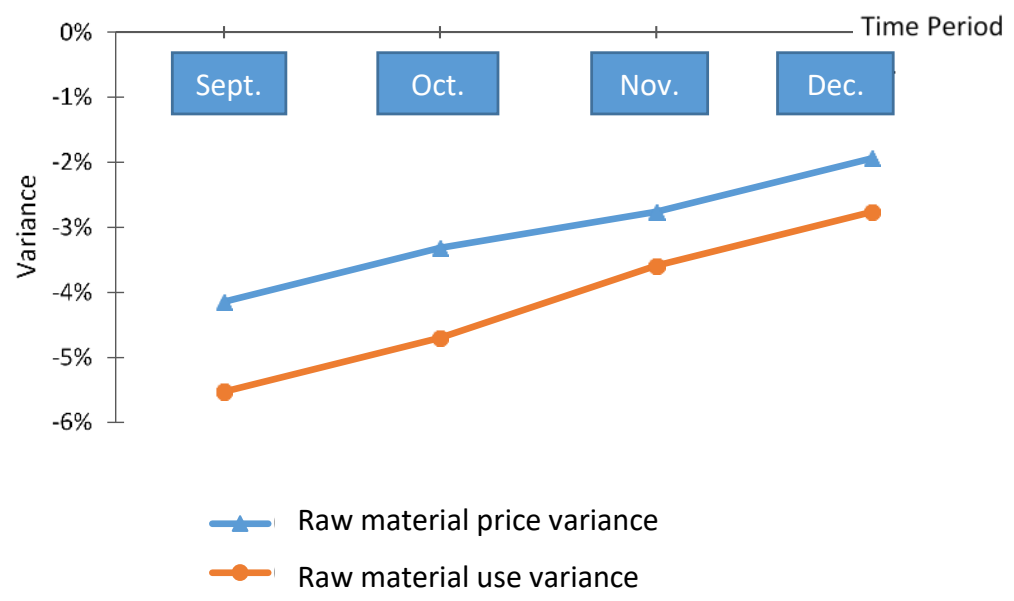

Figure 2. Graphic interpretation of the obtained results

Research into variance changes proves that with the decrease in raw material price, which in its turn decreased the unfavourable percentage price variance, the use of an ingredient in terms of its volume was close to its standard value, thus reducing the percentage variance of raw material usage. The analysis carried out enables us to make a conclusion that due to changes in both variances approaching zero, a more thorough analysis is not required on this stage. However, we believe, if we operated variances represented in absolute values only, it would be difficult to come to this conclusion.

Exploring variances we cannot ignore the reasons of their emergence, one of which, in our view, being uncontrolled factors. When setting a standard it is necessary to choose one representative value of an indicator, whereas there is a certain range of possible outcomes, even when international transactions are implemented under control.

This should be taken into consideration when exploring variances as an integral part of efficiency concept of international transactions.

In our view, under economic uncertainty, the standard that meets certain parameters acceptable for a beer manufacturing company, should be regarded as a range of possible values of an indicator, rather than a parameter expressed in one value. The range itself may be predicted, however, it is impossible to predict the exact indicator value within this range. And yet "making well-grounded and timely managerial decisions is impossible without accurate information" (Vasilchik, 2013 p.8). This task can be solved using Markovian processes, which can 
be demonstrated by the example below. A company producing upmarket beer has to determine the standard price of beer produced from imported raw material. Information obtained by a business entity when exploring the market of premium class beer indicated that the conditions of contracts between an importer and a foreign supplier allow to set a price within the range from 13 to 27 euro per one litre of beer.

Let us analyse system $S$, which refers to one litre of upmarket beer, and let us evaluate those conditions of this system, which are characterised by the market price of beer within the following ranges:

$s_{1}$ - from 13 еиго до 16 еurо;

$s_{2}$ - from 16 еuго до 22 euro;

$s_{3}$ - from 22 еurо до 24 еuro;

$s_{4}$ - от 24 еurо до 27 euro.

The market price of one litre of upmarket beer depends only on its current price at this point of time. The price of beer may change at any random moment as a result of accidental impact of the market. System $S$ transfer from one conditions into another occurs with probability densities fixed in time and values presented in Matrix (1):

$$
\rho=\left(\begin{array}{llll}
0 & 4 & 3 & 1 \\
2 & 0 & 1 & 7 \\
4 & 0 & 0 & 3 \\
6 & 1 & 2 & 0
\end{array}\right) .
$$

Based on the primary data, system $S$ features a discrete homogeneous continuous-time Markovian process. It means that the flows of events fostering system $S$ to transfer from one state into another are simple. The marked state graph is provided in Figure 3.

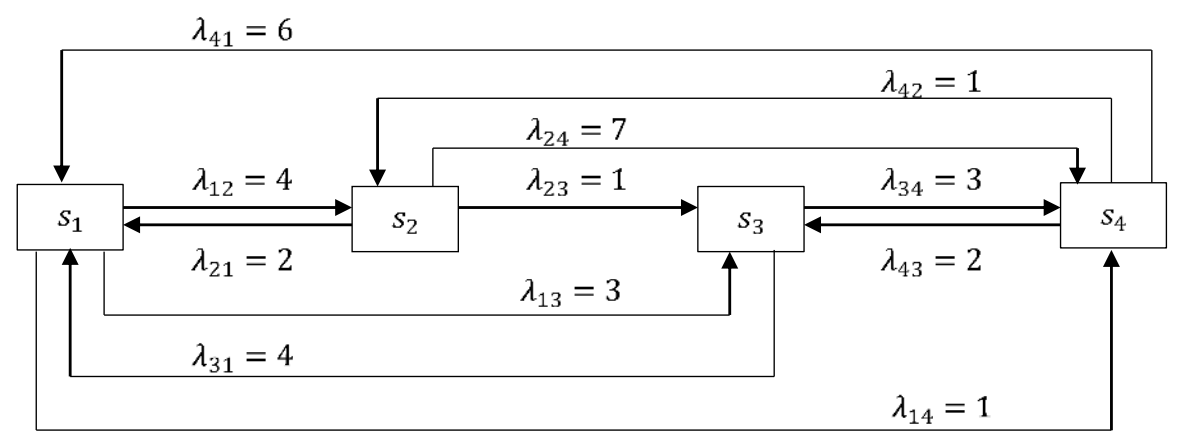

Figure 3. State graph of the system under study 
Graph analysis proves that system $S$ may transfer from one state into another in a finite number of steps, which means the system is ergodic. It is proved in [1 p. 115] that if the number of states of system $S$ is finite, this system is ergodic and all flows of events causing system $S$ to transfer from one state into another are simple, then there are final probabilities of states $\left(p_{i}\right)$ defined as follows:

$$
p_{i}=\lim _{t \rightarrow+\infty} p_{i}(t), i=1, \ldots, n
$$

where $p_{i}(t)$ - probability of state $s_{i}$ of system $S$ at the moment $t$.

In order to determine final probabilities there are good reasons to use the system of Kolmogorov differential equations, which is represented as follows [1. p.40]:

$$
\frac{d p_{i}(t)}{d t}=-\left(\sum_{j=1}^{n} \lambda_{i j}\right) p_{i}(t)+\sum_{j=1}^{n} \lambda_{i j} p_{j}(t), \quad i=1, \ldots, n ; \quad t \geq 0 .
$$

If in equation (3) we proceed to the limit under $t \rightarrow+\infty$, then it rearranges into the system of homogeneous algebraic linear equations in the $n$ unknowns of $p_{i}, i=1, \ldots, n$, shown as below [2 p. 125]

$$
-\left(\sum_{j=1}^{n} \lambda_{i j}\right) p_{i}+\sum_{j=1}^{n} \lambda_{i j} p_{j}=0, \quad i=1, \ldots, n
$$

because the probability of continuous random variable $p_{i}(t)$ under $t \rightarrow+\infty$ converge to contstant value $p_{i}$, while the derivative of a constant value equals zero. In view of the foregoing considerations, let us form a system of equations:

$$
\left\{\begin{array}{c}
-8 p_{1}+2 p_{2}+4 p_{3}+6 p_{4}=0 \\
4 p_{1}-10 p_{2}+p_{4}=0 \\
3 p_{1}+p_{2}-7 p_{3}+2 p_{4}=0 \\
p_{1}+7 p_{2}+3 p_{3}-9 p_{4}=0
\end{array}\right.
$$

By transforming the system of equations (5) we will obtain

$$
\left\{\begin{array}{l}
-8 p_{1}+2 p_{2}+4 p_{3}+6 p_{4}=0 \\
p_{3}=0.98 p_{4} \\
p_{2}=-0.8 p_{3}+1.45 p_{4} \\
p_{1}=2.6 p_{3}-1.15 p_{4}
\end{array}\right.
$$

or

$$
\left\{\begin{array}{c}
-8 p_{1}+2 p_{2}+4 p_{3}+6 p_{4}=0 ; \\
p_{3}=0.98 p_{4} ; \\
p_{2}=0.67 p_{4} ; \\
p_{1}=1.4 p_{4} .
\end{array}\right.
$$

Therefore, the general solution of system (5), depending on one arbitrary parameter $p_{3} \in[0,1]$, is vector

$$
\left(p_{1}=1.4 p_{4} ; \quad p_{2}=0.67 p_{4} ; \quad p_{3}=0.98 p_{4} ; \quad p_{4}\right) .
$$

By changing the first equation with a standard condition we will obtain a system, which makes it possible from the whole set of particular solutions to find the one meeting the required conditions:

where

$$
\left\{\begin{array}{l}
p_{1}+p_{2}+p_{3}+p_{4}=0 \\
p_{3}=0.98 p_{4} \\
p_{2}=0.67 p_{4} \\
p_{1}=1.4 p_{4}
\end{array}\right.
$$




$$
\left\{\begin{array}{l}
p_{1}=0.35 \\
p_{2}=0.17 \\
p_{3}=0.23 \\
p_{4}=0.25
\end{array}\right.
$$

As a result of calculations carried out it is possible to predict the market price of premium class beer, which means that after allowing sufficient time, there is a high probability that the price per one litre of upmarket beer will be within the range from 13 euro to 16 euro. That is why, an importer can refer to the price range from 13 to 16 euro per one litre of upmarket beer, thus exposing itself to a minimum risk level.

Thus, systematization of the findings carried out allows us to draw the following conclusions:

1. Variance analysis of actual results from the expected ones makes it possible to determine the progress of the company in its pursue of its goals, determined by international trade strategy, including import. Therefore, the process of variance analysis contains nothing to make it incompatible with the concept of efficiency enhancement of international trade transactions. Variance analysis is aimed at enhancing the efficiency of import operations, since it provides an increased company's focus on those processes requiring taking measures and not to waste time on those processes, where the results are in line with expectations.

2. A company should analyse only variances which are appropriate for the exploration. Therefore, for the purpose of analysis of different types of cost variances when carrying out import transactions, it is necessary to use the set criteria based on the factors due for consideration when making such a decision. It was determined that in order to identify trends in variance change it is relevant to use percentage variance graphs, which make it possible to represent them in temporal dynamics.

3. The revealed distinctive characteristics of exploring differences between actual and expected results when carrying out import transactions enabled us to formulate the principles, characteristic for the analysis of this type of international trade of a company. Application of these principles offers an opportunity to carry out a comprehensive analysis and systematization of internal environment factors, to define the procedure of an importer's actions, to form an information base of the subject under study, to develop methodology for variance analysis for international trade transactions.

4. The results obtained proved that in order to enhance the efficiency of international transactions, while analysing variances it is possible to apply such probability modelling as Markovian processes. These processes make it possible to predict the range of probable indicator changes under economic uncertainty, which allows avoiding inaccuracy in setting standards.

\section{References:}

[1] Labsker L.G. Probabilistic modelling in the financial-economic field [Text]: the Textbook / L.G. Labsker. - The second edition. - M: INFRA-M, 2014. - pp. 172.

[2] Martyanova O.V. Model of the impact assessment price risks in the conditions uncertainty on efficiency of the foreign trade business activities with use of hedging and 
markov processes [Text] / O.V. Martyanova // Audit and financial analysis. - 2016. № 4. - P. 113-126.

[3] Producers of malt and brewers will shall "adapt by difficult year [Electronic resource]. URL: http://e-malt.ru/News.asp?Command=ArticleShow\&ArticleID $=4674$

[4] Vasilchuk O. I. Use of the management decisions [Text] this managerial accounting in case of acceptance / O. I. Vasilchuk // The Karelian scientific magazine. - 2013. - № 2. - P. 8-10. 